\title{
Linear polyethylenimine produced by partial acid hydrolysis of poly(2-ethyl-2-oxazoline) for DNA and siRNA delivery in vitro
}

This article was published in the following Dove Press journal:

International Journal of Nanomedicine

30 October 2013

Number of times this article has been viewed

\author{
Julio C Fernandes' \\ Xingping Qiu ${ }^{2}$ \\ Françoise MWinnik ${ }^{2,5}$ \\ Mohamed Benderdour \\ Xiaoling Zhang ${ }^{3,4}$ \\ Kerong Dai ${ }^{3,4}$ \\ Qin Shi'
}

'Orthopaedics Research Laboratory, Research Centre, Sacré-Coeur Hospital, ${ }^{2}$ Faculty of Pharmacy and Chemistry, University of Montreal, Montreal, Quebec, Canada; ${ }^{3}$ Orthopaedic Cellular and Molecular Biology Laboratories, Institute of Health Sciences, Chinese Academy of Sciences, ${ }^{4}$ Department of Orthopaedics, Ninth People's Hospital, Shanghai Jiao Tong University School of Medicine, Shanghai, People's Republic of China; ${ }^{5}$ WPI International Center for Materials Nanoarchitectonics, National Institute for Materials Science, Ibaraki, Tsukuba, Japan
Correspondence: Qin Shi

Orthopaedics Research Laboratory,

Research Centre, Sacré-Coeur

Hospital, University of Montreal,

5400 Gouin Blvd West, Montreal,

Quebec, Canada H4J IC5

Tel +5I 43382222 extn 3043

Fax +5। 43382694

Email qin.shi@umontreal.ca

\begin{abstract}
Polyethylenimines (PEIs) are the most efficient synthetic vectors for gene delivery available to date. With its high charge density and strong proton-buffering effect, PEI has an ability to condense DNA and small interfering RNA at physiologic $\mathrm{pH}$. However, the polymer suffers from the disadvantage of high cellular toxicity. To reduce its cellular toxicity, we synthesized linear PEIs by partial hydrolysis of poly(2-ethyl-2-oxazoline). Three linear PEIs with different hydrolysis percentages $(30 \%, 70 \%$, and $96 \%$, respectively) were produced as PEI30, PEI70, and PEI96. PEI30 and PEI96 cannot be considered as suitable transfection agents because of low transfection efficiency (PEI30) or high cellular toxicity (PEI96). PEI70 displayed very weak cell toxicity. The charge density of this polymer (PEI70) was strong enough to condense DNA and small interfering RNA at a physiologic $\mathrm{pH}$ of 7.4. Our results also show that PEI70 was highly efficient in DNA delivery and small interfering RNA-mediated knockdown of target genes. Thus, polymers such as PEI70 appear to be very promising vectors for gene delivery.
\end{abstract}

Keywords: nonviral vector, polyethylenimine, gene delivery, DNA, small interfering RNA

\section{Introduction}

Gene transfer has been used widely as a research tool to study gene regulation and control. Gene therapy, ie, the treatment of human diseases by gene transfer, is becoming a promising application against various inherited or acquired diseases. It offers controlled, specific delivery of nucleic acid (DNA and RNA) to targeted cells, leading to treatments that are less invasive, more effective, and less expensive than existing modalities. However, a large size and negative surface charge density most likely limit DNA uptake by negatively charged cell membranes via nonspecific endocytosis. Small interfering RNA (siRNA) alone cannot penetrate the cell membrane because of its highly charged backbone. It is more susceptible than DNA to nuclease destruction. Therefore, the primary challenge for gene therapy is to develop carriers (vectors) capable of efficiently protecting and delivering genes to targeted cells with minimal toxicity. Different vector systems have been tested in gene transfer studies for potential clinical use. Viral gene therapy consists of using viral vectors which, given their structure and mechanisms of action, are good models to carry therapeutic genes efficiently, leading to long-term expression. However, viral vectors can cause several problems for patients, ie, toxicity, oncogenic effects, and immune and inflammatory responses. Synthetic and natural cationic (positively charged) polymers have been used widely to carry negatively charged DNA and condense it into small particles, facilitating cellular internalization via endocytosis through charge-charge interactions with anionic sites on cell surfaces. ${ }^{1}$ 
Certain nonviral vectors are limited as gene carriers by typically low transfection efficiency and transient gene expression (eg, chitosan). Polyethylenimines (PEIs), a series of synthetic polymers, are well known to be effective cationic polymers, demonstrating high transfection efficiency in vitro and in vivo. PEIs exist as either branched or linear structures. While branched PEI is normally synthesized via acidcatalyzed polymerization of aziridine, ${ }^{2}$ linear PEI is produced in two steps. Poly(2-ethyl-2-oxazoline) (PEtOx) is obtained by living polymerization of 2-ethyl-2-oxazoline, followed by acid hydrolysis. ${ }^{3,4}$ It has been demonstrated that the transfection level is closely related to polymer molecular weight, the charge ratio of polymer to DNA/siRNA, particle size, and zeta potential. The transfection efficiency of PEIs increases with increasing molecular weight. High molecular weight PEI results in high cytotoxicity. The optimal molecular weight of a PEI-DNA formation is 5-25 kDa. ${ }^{5}$ Most of the PEIs used for gene transfer are highly branched species. A previous study demonstrated the effective delivery of DNA and siRNA with linear PEI in vivo. ${ }^{6}$ Linear PEI has lower cytotoxicity, but is also less effective in condensing DNA than branched PEI. PEI-based gene transfer technology is starting to reach the market as commercial transfection agents, including the DNA transfection agent jet-PEI ${ }^{\circledR}$ (Polyplus-transfection Inc, Illkirch, France), using a linear derivative of PEI. DNA transfection with linear PEI, obtained by acid hydrolysis of PEtOx with varying acid volume, has been demonstrated. ${ }^{3}$ However, most studies of linear PEI-siRNA were performed with commercial PEI products, which contained significant amounts of N-acyl residues that limited gene transfection. ${ }^{?}$

In the present investigation, we aimed to synthesize low molecular weight linear PEI (10 kDa) containing different amounts of ethylenimine units. Partial hydrolysis of PEtOx was achieved, by varying acid hydrolysis duration, for reducing the cellular toxicity of PEI. The potential of such linear PEIs as DNA and siRNA delivery vectors was explored in vitro.

\section{Materials and methods Materials}

2-Ethyl-2-oxazoline (99\%), $p$-toluenesulfonyl chloride $(99+\%)$, the $\beta$-galactosidase reporter gene activity detection kit, and other chemicals were sourced from Sigma-Aldrich Chemical Co (St Louis, MO, USA), if not stated otherwise. Dulbecco's Modified Eagle's Medium, fetal bovine serum, $0.25 \%$ trypsin-ethylenediaminetetraacetic acid (EDTA) solution, penicillin-streptomycin mixture, Lennox L Broth Base $^{\circledR}$, agarose, ethidium bromide, Lipofectamine ${ }^{\mathrm{TM}} 2000$, and oligofectamine reagent were obtained from Invitrogen Canada Inc (Burlington, ON, Canada). The plasmid DNA VR1412 encoding the $\beta$-galactosidase reporter gene with a cytomegalovirus promoter was obtained from Vical Inc (San Diego, CA, USA). QIAfilter plasmid mega kits were supplied by Qiagen (Mississauga, ON, Canada). Sjögren syndrome antigen- (SSB, GenBank accession number NM_009278) targeted siRNA was provided by Merck \& Co., Inc. (West Point, PA, USA). SSB-siRNA was selected as validated siRNA to evaluate our delivery strategies.

\section{PEtOx preparation}

2-Ethyl-2-oxazoline (99\%) and $p$-toluenesulfonyl chloride (99+\%) were dried and vacuum-distilled over calcium hydride before use. Acetonitrile was purified in a solvent system via two packed columns of activated alumina provided by Innovative Technology Inc (Cartersville, GA, USA). Water was deionized in a MilliQ system (EMD Millipore, Bedford, MA, USA).

Polymerization was undertaken according to a reported procedure with slight modification. ${ }^{8}$ Typically, a round-bottom flask equipped with $N_{2}$-filled condenser and rubber stopper was charged with 2-ethyl-2-oxazoline ( $6 \mathrm{~mL}, 60 \mathrm{mmol})$, acetonitrile $(20 \mathrm{~mL})$, and methyl $p$-tosylate $(90 \mu \mathrm{L}, 0.6 \mathrm{mmol})$ via an oxygen-free syringe at room temperature. After mixing, the flask was immersed in an oil bath preheated to $65^{\circ} \mathrm{C}$. Polymerization was continued for 60 hours with stirring. Next, $5 \mathrm{~mL}$ of $\mathrm{KOH}$ methanol solution $(1.0 \mathrm{M})$ was added to quench poly(2-isopropyl-2-oxazoline) oxazolinium living end groups. The termination reaction was continued for 12 hours at $65^{\circ} \mathrm{C}$. Thereafter, the polymerization solution was cooled to room temperature, and diluted with deionized water to $80 \mathrm{~mL}$, then dialyzed against deionized water for 3 days with a 3,500 Da molecular weight cutoff membrane. The purified polymer was recovered by freeze-drying. The yield was $4.8 \mathrm{~g}$, $80 \%$. Gel permeation chromatography: $\mathrm{Mn}=1.05 \times 10^{4}$. ${ }^{1} \mathrm{H}$-nuclear magnetic resonance (NMR) $\left(\mathrm{CDCl}_{3}, \delta\right) \mathrm{ppm}: 0.96$ (br, $\left.-\mathrm{CH}_{2} \mathrm{CH}_{3}\right), 2.25$ (br, $\left.-\mathrm{CH}_{2} \mathrm{CH}_{3}\right), 3.45(\mathrm{br},-\mathrm{N}(\mathrm{C}=\mathrm{O})$ $\mathrm{CH}_{2} \mathrm{CH}_{2}-$ ). Fourier transform infrared spectroscopy $(\mathrm{KBr}$, $\left.\mathrm{cm}^{-1}\right), v$ 2,976, 2,934, 2,873, 1,646, 1,474, 1,431, 1,205, $1,160,1,089$, and $755 \mathrm{~cm}^{-1}$.

\section{Partial acid hydrolysis of PEtOx}

Hydrolysis was performed in a round-bottom flask equipped with a magnetic stirrer and condenser. ${ }^{3}$ Typically, $1.0 \mathrm{~g}$ of PEtOx was dissolved in $5 \mathrm{~mL}$ of deionized water. After dissolution, $10 \mathrm{~mL}$ of $\mathrm{HCl}$ solution $(10 \mathrm{w} / \mathrm{w} \%)$ was added. The solution was refluxed at $100^{\circ} \mathrm{C}$ for a few hours. It was then 
cooled to room temperature and neutralized to $\mathrm{pH} 9-10$ by $5 \mathrm{~N} \mathrm{NaOH}$ solution. The neutralized polymer solution was dialyzed against deionized water for 3 days with a 5,000 Da molecular weight cutoff membrane. The polymer was recovered by freeze-drying. Yield was $0.4-0.6 \mathrm{~g}$. Polymer characteristics were analyzed by ${ }^{1} \mathrm{H}-\mathrm{NMR}$ spectroscopy (ARX-400 400 MHz, Bruker Corporation, Billerica, MA, USA). The solvent was deuterium oxide $\left(\mathrm{D}_{2} \mathrm{O}\right)$. Ultravioletvisible spectra were measured in an $8452 \mathrm{~A}$ photodiode array spectrometer (Hewlett Packard, Palo Alto, CA, USA). Polymer concentration was $10 \mathrm{wt} \%$ in $1 \mathrm{M} \mathrm{NaCl}$. The degree of hydrolysis was evaluated by ${ }^{1} \mathrm{H}-\mathrm{NMR}$, by comparing the integration of resonances at $2.90\left(-\mathrm{NHCH}_{2}-\right)$ and 3.45 $\left(-\mathrm{N}(\mathrm{C}=\mathrm{O}) \mathrm{CH}_{2}-\right) \mathrm{ppm}$, and was found to be 31,70 , and $96 \mathrm{~mol} \%$ for polymers hydrolyzed for 3,5 , and 7 hours.

\section{Plasmid DNA amplification and purification}

Plasmid DNA VR1412 was purified using a Qiagen QIAfilter plasmid mega kit, according to the manufacturer's instructions, and resuspended in water. Purity was confirmed by $0.8 \%$ agarose gel electrophoresis and DNA absorption at $260 \mathrm{~nm}$.

\section{Linear PEI-DNA or PEI-siRNA complex preparation}

PEIs of different hydrolysis percentages were dissolved in $\mathrm{NaCl}$ buffer (150 mM, pH 7.4) to form solutions of $10 \mathrm{mg} / \mathrm{mL}$ and passed through a $0.22 \mu \mathrm{m}$ filter. PEI-DNA and PEIsiRNA complexes were produced by mixing $5 \mu \mathrm{g}$ DNA or siRNA in $50 \mu \mathrm{L}$ of $150 \mathrm{mM} \mathrm{NaCl}$ with various amounts of PEI stock solutions in $150 \mathrm{mM} \mathrm{NaCl}$, resulting in various $\mathrm{N} / \mathrm{P}$ ratios in a final volume of $100 \mu \mathrm{L}$. The nanoparticles were incubated for 30 minutes at room temperature and tested without further modifications.

\section{Particle size}

Particle size was measured with a Nano ZS90 Zetasizer (Malvern Instruments Ltd, Malvern, UK). First, $100 \mu \mathrm{L}$ of PEI-DNA or PEI-siRNA complexes at different N/P ratios were obtained as indicated earlier. The final volume of 100 $\mu \mathrm{L}$ was processed with disposable, low-volume polystyrene $(100 \mu \mathrm{L})$ cuvettes. Particle size was measured in triplicate.

\section{Zeta potential}

The zeta potential of PEI-DNA and PEI-siRNA complexes was quantified by Nano ZS90 Zetasizer based on the principle of phase analysis light scattering. First, $100 \mu \mathrm{L}$ of PEI-DNA or PEI-siRNA complexes at different N/P ratios were generated, as indicated earlier. The solution was then diluted to $1 \mathrm{~mL}$ with $\mathrm{NaCl}$ buffer. Measurements were in triplicate in disposable zeta potential capillary cells.

\section{Evaluation of siRNA integrity by agarose gel electrophoresis after synthesis}

DNA and siRNA binding with PEI was measured by $0.8 \%$ or $2 \%$ agarose gel electrophoresis in Tris-borate EDTA buffer (4.45 mM Tris-base, $1 \mathrm{mM}$ sodium EDTA, $4.45 \mathrm{mM}$ boric acid) at $\mathrm{pH}$ 8.0. A series of different PEI to DNA or siRNA N/P ratios was loaded $(20 \mu \mathrm{L}$ of sample containing $1 \mu \mathrm{g}$ of DNA or siRNA) on gel, and electrophoresis was carried out at $55 \mathrm{~V}$ for 120 minutes. The gel was stained with ethidium bromide $(0.5 \mu \mathrm{g} / \mathrm{mL})$ and photographed in a MultiImage ${ }^{\mathrm{TM}}$ light cabinet (Alpha Innotech Corporation, San Leandro, CA, USA).

\section{Cell culture and transfection protocol in vitro}

HeLa cervical carcinoma cells were obtained from the American Type Culture Collection (Rockville, MD, USA) and grown in Dulbecco's Modified Eagle's Medium supplemented with $10 \%$ fetal bovine serum and $1 \%$ penicillinstreptomycin. Cultured in a $5 \%-95 \% \mathrm{CO}_{2}-\mathrm{O}_{2}$ atmosphere at $37^{\circ} \mathrm{C}$, they were seeded, 24 hours prior to transfection, on 24-well plates at a density of 50,000 cells/well in $1 \mathrm{~mL}$ of their usual culture medium supplemented with $10 \%$ fetal bovine serum and $1 \%$ penicillin-streptomycin. On the day of transfection, the culture medium was replaced by 900 $\mu \mathrm{L}$ of serum-free Dulbecco's Modified Eagle's Medium and $100 \mu \mathrm{L}$ of PEI-DNA or PEI-siRNA complexes containing either free DNA or siRNA, polymer-DNA or polymersiRNA complexes with DNA or siRNA equivalent to 5 $\mu \mathrm{g}$. After a 6-hour incubation, the cells received $1 \mathrm{~mL}$ of complete medium and were incubated for 60 hours posttransfection.

\section{Cell viability}

The cells were seeded and transfected with free DNA or siRNA, PEI-DNA or PEI-siRNA complexes, then incubated for 24 hours at a temperature of $37^{\circ} \mathrm{C}$. Cell viability was evaluated by the 3-[4,5-dimethylthiazol-2-yl]-2,5-diphenyl tetrazolium bromide (MTT, Sigma-Aldrich Chemical Co) colorimetric assay based on reduction of MTT to water-insoluble formazan by mitochondria in viable cells. Absorbance was measured at $570 \mathrm{~nm}$ with a universal 
microplate reader (EL800, Molecular Devices Corporation, Menlo Park, CA, USA).

\section{Determination of transfection efficiency}

The VR1412 gene codes for $\beta$-galactosidase, an enzyme that catalyzes the hydrolysis of $\beta$-galactosides. Expression of $\beta$-galactosidase activity was analyzed using a $\beta$-galactosidase reporter gene activity detection kit (Sigma-Aldrich Chemical $\mathrm{Co}$ ) according to the manufacturer's instructions. Briefly, the cells were lysed for 60 hours after transfection with lysis buffer included in the kit, and the cell extracts were centrifuged at maximum speed for 15 minutes at $4^{\circ} \mathrm{C}$ to remove any debris. The reaction was quantified in a microplate reader (Molecular Devices Corporation). Total protein content of the samples was measured using a bicinchoninic acid protein $\operatorname{assay}^{9}$ (Pierce, Rockford, IL, USA).

\section{Evaluation of transfection efficiency by RT-PCR}

Total RNA was extracted from cells with TRIzol reagent (Invitrogen Canada Inc) according to the manufacturer's specifications. RNA was quantified with a RiboGreen RNA quantitation kit (Molecular Probes, Eugene, OR, USA). For real-time reverse transcription polymerase chain reaction (RT-PCR) analysis, $1 \mu \mathrm{g}$ of total RNA was reversetranscribed with reverse transcription kits (Qiagen), as detailed in the manufacturer's guidelines. One-fifth of the reverse transcriptase reaction was analyzed by RT-PCR. The following primers were used: SSB, forward 5'-CCA AAA TCT GTC ATC AAA TTG AGT ATT-3', reverse
5'-CCA GCC TTC ATC CAG TTT TAT CT-3'; ${ }^{10} \beta$-actin housekeeping gene, forward $5^{\prime}$-AGC CTC GCC TTT GCC GA-3', reverse 5'-CTG GTG CCT GGG GCG-3'. ${ }^{11}$ SSB mRNA expression in cultured cells was expressed as fold changes relative to control conditions (unstimulated cells) according to the $\Delta \Delta \mathrm{C}_{\mathrm{T}}$ method detailed in the manufacturer's guidelines (Stratagene, La Jolla, CA, USA). A $\Delta \mathrm{C}_{\mathrm{T}}$ value was calculated first by subtracting the $C_{T}$ value for the $\beta$-actin housekeeping gene from each sample. $\mathrm{A} \Delta \Delta \mathrm{C}_{\mathrm{T}}$ value was then calculated by subtracting the $\Delta \mathrm{C}_{\mathrm{T}}$ value of the control from the $\Delta \mathrm{C}_{\mathrm{T}}$ value of each treatment. Fold changes relative to the controls (unstimulated cells) were then determined by raising 2 to the power of $\Delta \Delta \mathrm{C}_{\mathrm{T}}$. Each PCR was performed in triplicate on two separate occasions in at least three independent experiments.

\section{Statistical analysis}

The data are expressed as the mean \pm standard error of the mean of at least three independent experiments. All statistics were generated by Prism software (GraphPad Software, San Diego, CA, USA). Statistical significance was analyzed by unpaired Student's $t$-test, and $P<0.05$ was considered to be statistically significant.

\section{Results}

\section{$\mathrm{PEtOx}$ polymerization and hydrolysis}

Linear PEI was synthesized in two steps (Figure 1). First, PEtOx oligomers, which are precursors of linear PEIs, were synthesized by living cationic polymerization of 2-ethyl2-oxazoline (Figure 1A). The reaction was initiated with
A

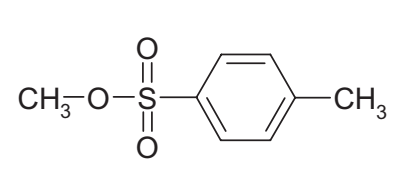

Polymerization

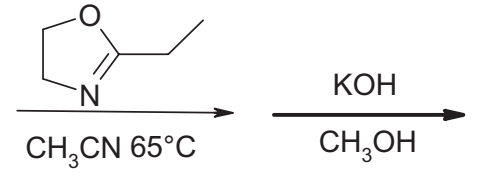

$\mathrm{CH}_{3} \mathrm{CN} 65^{\circ} \mathrm{C}$

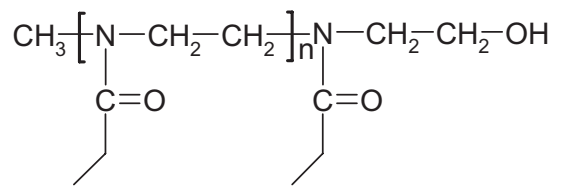

Poly(2-ethyl-2-oxazoline) (PEtOx)<smiles>CCC(=O)N(C)CCCC(C)NCCOO</smiles>

Acid hydrolysis

Poly[(2-ethyl-2-oxazoline)-co-(ethylene imine)] (L-PEI)

Figure I Reaction scheme for synthesis of linear PEl and structure of the polymer. (A) Polymerization of 2-ethyl-oxazoline and (B) acid hydrolysis of poly(2-ethyl-2-oxazoline). Abbreviation: L-PEl, linear polyethylenimine. 
p-toluenesulfonyl chloride in acetonitrile at $65^{\circ} \mathrm{C}$, followed by termination with $\mathrm{KOH}$ solution. Such polymerization achieves the low molecular weight and narrow distributions required for PEtOx application as a gene delivery vector.

Second, linear PEIs were prepared by acid hydrolysis of PEtOx with an excess of hydrochloric acid (Figure 1B). Three linear PEI derivatives were obtained by sampling a single hydrolysis mixture at various time intervals. As hydrolysis time increased, the extent of hydrolysis grew, as reported in Table 1. Hydrolysis percentages of PEtOx molecular weight 10,000 at various hydrolysis times of 3,5 , and 7 hours were $30 \%, 70 \%$, and $96 \%$, respectively. Figure 2 shows the ${ }^{1} \mathrm{H}-\mathrm{NMR}$ spectrum of linear PEI derivatives in $\mathrm{D}_{2} \mathrm{O}$. The hydrolysis percentage of linear PEI was evaluated by ${ }^{1} \mathrm{H}-\mathrm{NMR}$ by comparing the integration of resonances at $2.90\left(-\mathrm{NHCH}_{2}-\right.$, peak d) and $3.45(-\mathrm{N}(\mathrm{C}=\mathrm{O})$ $\mathrm{CH}_{2}-$, peak c) ppm. The peak of various methylene groups (peak d) corresponded to ethyleneimine units $(2.9 \mathrm{ppm})$ and ethyleneimine units substituted by $\left(-\mathrm{N}(\mathrm{C}=\mathrm{O}) \mathrm{CH}_{2}-\right)$ side groups ( $3.45 \mathrm{ppm}$, peak c). The ratio of the areas of these peaks allowed the determination of ethyleneimine unit content.

\section{PEl cytotoxicity}

The cytotoxicity of acid hydrolysis of PEtOx samples was examined by MTT assay of human HeLa cells. Figure 3A presents the polymer composition dependence of cell viability after a 24-hour incubation of cells with $1 \mathrm{mg} /$ $\mathrm{mL}$ polymer solution. PEI30 (30\% hydrolyzed PEtOx) and PEI70 (70\% hydrolyzed PEtOx) were nontoxic compared with the controls, ie, nontreated cells. Viability decreased dramatically by $8.7 \% \pm 0.54 \%(\mathrm{n}=3, P<$ 0.001) when the cells were incubated with PEI96 (96\% hydrolyzed PEtOx), in comparison with nontreated cells. Figure $3 \mathrm{~B}$ reports on cell viability after a 24 -hour incubation with different concentrations (0 to $3 \mathrm{mg} / \mathrm{mL}$ ) of polymer solutions. $\mathrm{IC}_{50}$ values for PEIs of different acid hydrolysis were $14.29 \mathrm{mg} / \mathrm{mL}$ (PEI30 of 30\% hydrolyzed

Table I Acid hydrolysis of $\mathrm{PEtOx}$ at $100^{\circ} \mathrm{C}$ and compositions of linear PEI

\begin{tabular}{llll}
\hline Polymer & MW (PEtOx) & $\begin{array}{l}\text { Hydrolysis time } \\
\text { (hours) }\end{array}$ & $\begin{array}{l}\text { Percent } \\
\text { hydrolysis (\%) }\end{array}$ \\
\hline PEI30 & $10 \mathrm{kDa}$ & 3 & 30 \\
PEI70 & $10 \mathrm{kDa}$ & 5 & 70 \\
PEI96 & $10 \mathrm{kDa}$ & 7 & 96 \\
\hline
\end{tabular}

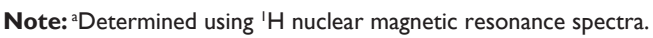

Abbreviations: PEI, polyethylenimine; PEtOx, poly(2-ethyl-2-oxazoline); MW, molecular weight.
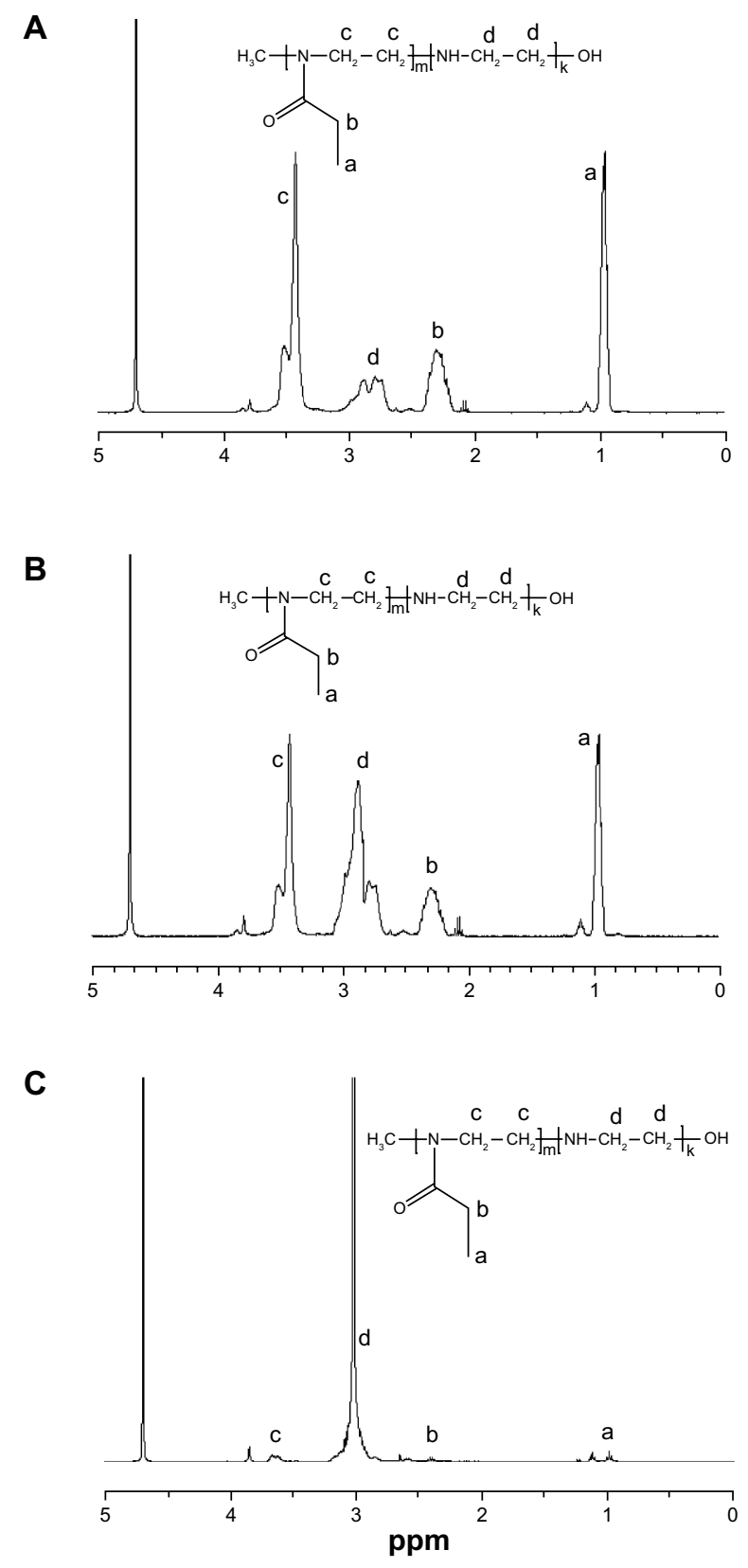

Figure 2 'H nuclear magnetic resonance spectrum of (A) PEI30, (B) PEI70, and (C) PEI96 (solvent: $\mathrm{D}_{2} \mathrm{O}$ ). The segment ratio of EtOx/El is estimated from the integration of methylene protons of $c$ and $d$ resonance.

Abbreviations: El, ethylenimine; $\mathrm{PEI}$, polyethylenimine; EtOx, ethyl-2-oxazoline; PEI30, 30\% hydrolyzed PEtOx; PEI70, 70\% hydrolyzed PEtOx; PEI96, 96\% hydrolyzed PEtOx; MTT, 3-[4,5-dimethylthiazol-2-yl]-2,5-diphenyl tetrazolium bromide.

PEtOx), $7.08 \mathrm{mg} / \mathrm{mL}$ (PEI70 of 70\% hydrolyzed PEtOx), and $0.025 \mathrm{mg} / \mathrm{mL}$ (PEI96 of 96\% hydrolyzed PEtOx), respectively.

\section{DNA inclusion and integrity}

We assessed plasmid DNA VR1412 containing $\beta$-galactosidase gene condensation and the integrity of these three PEIs by gel electrophoresis analysis. Linear 

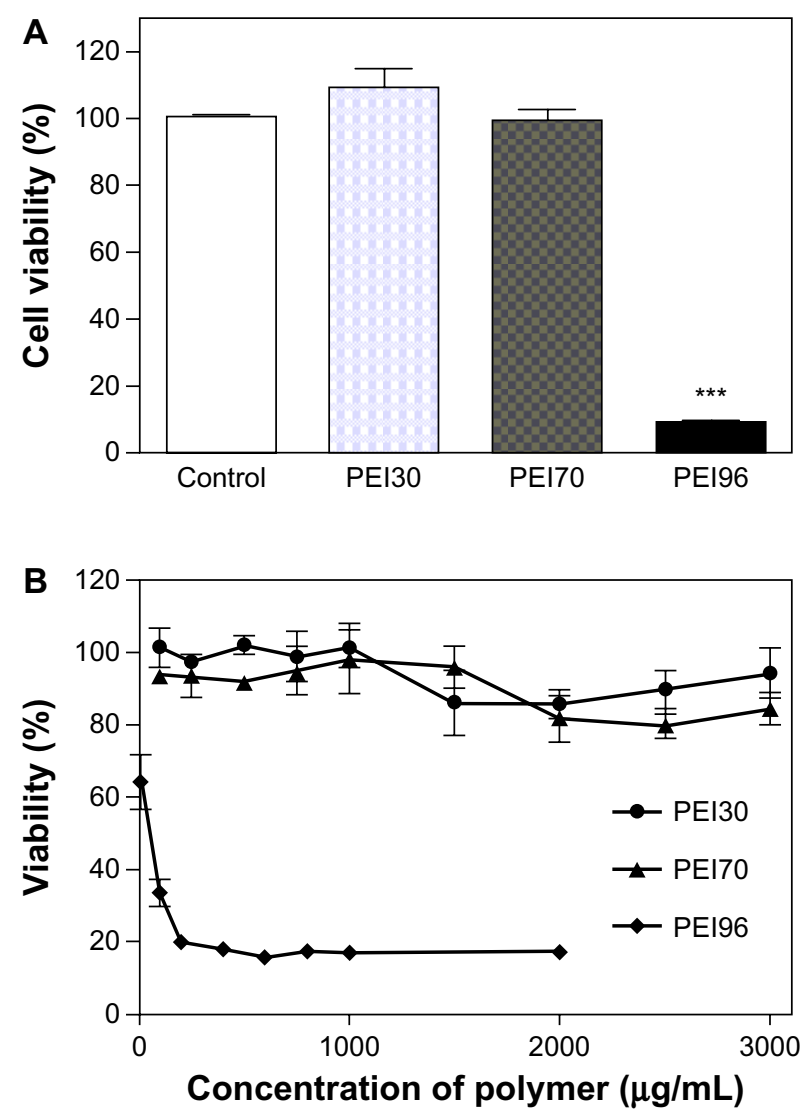

Figure 3 (A) Effect of acid hydrolysis of poly(2-ethyl-2-oxazoline) on HeLa cell viability evaluated by the MTT assay following incubation of cells for 24 hours at $37^{\circ} \mathrm{C}$ in the presence of polymer (I.0 g/L): I, control; 2, PEI30; 3, PEI70; and 4, PEI96. (B) Determination of $\mathrm{IC}_{50}$ by the MTT assay in HeLa cells. Viability is compared with nontreated cells, which are considered as $100 \%$. The $I_{50}$ represents the concentration at which $50 \%$ of cell growth was inhibited. Statistical significance was assessed by unpaired Student's $t$-test, $* * * P<0.001$.

Abbreviations: PEI, polyethylenimine; MTT, 3-[4,5-dimethylthiazol-2-yl]-2,5diphenyl tetrazolium bromide; $\mathrm{IC}_{50}$, half maximal inhibitory concentration; PEI30, 30\% hydrolyzed PEtOx; PEI70, 70\% hydrolyzed PEtOx; PEI96, 96\% hydrolyzed PEtOx.

PEI-DNA complexes were synthesized at different N/P ratios of linear PEI/DNA. N/P ratios were calculated on the basis of linear PEI nitrogen per DNA phosphate. ${ }^{12}$ Figure 4 shows the gel retardation result of linear PEIDNA complexes with increasing N/P ratios for samples of 30\% hydrolyzed PEtOx (PEI30, Figure 4A), 70\% hydrolyzed PEtOx (PEI70, Figure 4B), and 96\% hydrolyzed PEtOx (PEI96, Figure 4C). Intact $\beta$-galactosidase plasmid DNAs, before nanoparticle synthesis, are seen in lane 2 (Figure 4A-C). Complete retardation of PEI30/DNA was apparent at the N/P ratio of 10 (Figure 4A). However, both PEI70 and PEI96 started to form stable complexes at the N/P ratio of 3 . Taken together, these results show that the efficiency of complexation is related to the fraction of $-\mathrm{N}(\mathrm{C}=\mathrm{O}) \mathrm{CH}_{2}-$ groups. The higher the hydrolysis of ethyleneimine units, the more efficient is neutralization of the DNA phosphate groups.
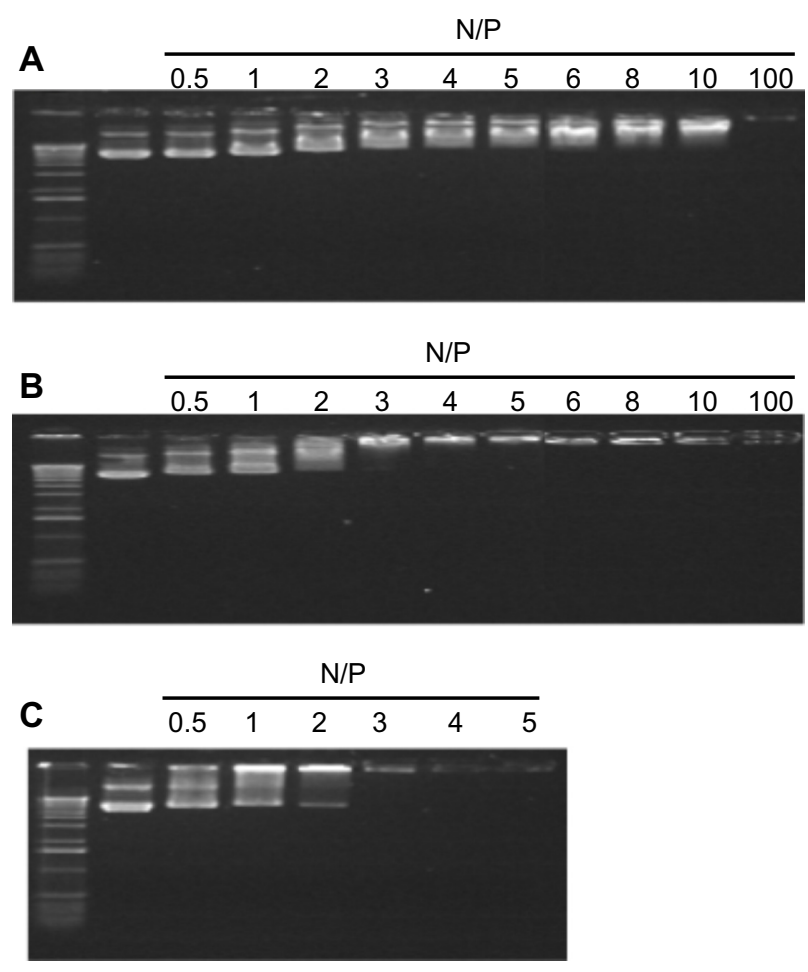

Figure 4 Electrophoresis analysis on $0.8 \%$ agarose gel. (A) PEI30-DNA, (B) PEI70DNA, and (C) PEI96-DNA. Effect of different percentages of acid hydrolysis of poly(2-ethyl-2-oxazoline) on DNA binding efficiency at N/P ratios (polymer to DNA) from 0.5:I to I00: I. Lane I, ladder I Kb; lane 2, free naked DNA (I $\mu \mathrm{g} / \mathrm{lane}$ ). Abbreviations: PEI, polyethylenimine; PEI30, 30\% hydrolyzed PEtOx; PEI70, 70\% hydrolyzed PEtOx; PEI96, 96\% hydrolyzed PEtOx.

\section{Zeta potential}

Solutions of different N/P ratios of PEI30-DNA, PEI70-DNA, and PEI96-DNA were prepared to measure their zeta potential. Zeta potential allows the measurement of surface charge of polymeric complexes, representing a critical factor in their interaction with cellular membranes. As shown in Figure 5A, zeta potential was directly proportional to N/P ratio. The zeta potentials of PEI30-DNA synthesized at any N/P ratios were negative. For PEI70 and PEI96, when the N/P ratio of all these polymeric/DNA complexes was around 1, the zeta potential was below zero, which could be attributed to the negatively charged phosphate groups in plasmid DNA and suggests plasmid DNA not bound by polymer. When PEI70 and PEI96 were mixed with plasmid DNA at the N/P ratio of 5 , the zeta potential changed from negative to positive. At N/P ratios between 5 and 100, the zeta potential increased slightly. PEI70-DNA and PEI96-DNA complexes all had moderate positive surface charges.

\section{Particle size}

Particle size is a crucial factor in cellular uptake of polymeric complexes. The influence of different hydrolysis percentages 

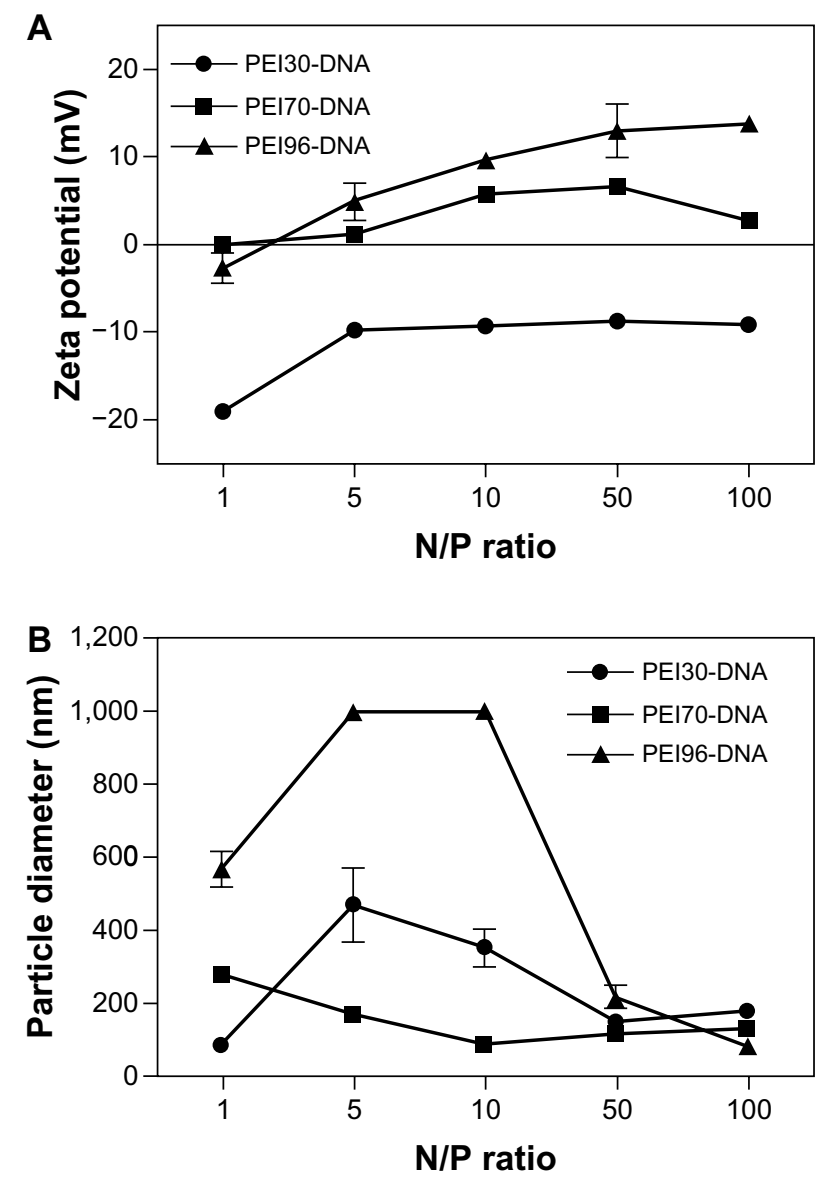

Figure $\mathbf{5}$ Characterization of polymer-DNA complexes. The zeta potential $(\mathrm{mV})$ (A) and size $(\mathrm{nm})(\mathbf{B})$.

and N/P ratios on polymer and DNA complex sizes was monitored by dynamic light scattering assay. The particle size of the PEI-DNA complexes was measured (Figure 5B). The particle size of PEI30-DNA varied between $87.20 \pm 8.69 \mathrm{~nm}$ in diameter $(\mathrm{n}=3, \mathrm{~N} / \mathrm{P}$ ratio $=1)$ and $470.33 \pm 101.3 \mathrm{~nm}$ in diameter $(n=3, N / P$ ratio $=5)$. When the N/P ratio of PEI70DNA nanoparticles was 1 , the nanoparticle size was around $279.67 \pm 7.86 \mathrm{~nm}$ in diameter $(\mathrm{n}=3$, Figure $5 \mathrm{~B})$ and zeta potential was close to zero (Figure $5 \mathrm{~A}$ ). When the N/P ratio increased, the PEI70-DNA nanoparticle size decreased to $116.83 \pm 4.04 \mathrm{~nm}(\mathrm{n}=3, \mathrm{~N} / \mathrm{P}$ ratio $=50)$ and the zeta potential increased past $6 \mathrm{mV}$. For PEI96 (96\% hydrolyzed PEtOx), larger particles $(1,000 \mathrm{~nm})$ were generated at N/P ratios of 1 , 5, and 10. Compact complexes of PEI96-DNA formed at the $\mathrm{N} / \mathrm{P}$ ratio of $50(217.33 \pm 30.94 \mathrm{~nm}$ in diameter, $\mathrm{n}=3)$ and $100(86.77 \pm 7.12 \mathrm{~nm}$ in diameter, $\mathrm{n}=3$, Figure $5 \mathrm{~B})$.

\section{Cytotoxicity of PEI-DNA complexes}

To investigate the cytotoxicity of PEI/DNA complexes, cell viability was examined by MTT assay after a 24-hour incubation (Figure 6A). Cells without PEI/DNA complex treatment were considered as controls, with cell viability of $100 \%$. Figure 6A shows the effects of PEIs of different acid hydrolysis to DNA N/P ratio on cell viability. Viable cells decreased slightly upon contact with free DNA $(5 \mu \mathrm{g} /$ well in 24-well plates, 89.5\%) in comparison with untreated cells. DNA-Lipofectamine $20005 \mu \mathrm{g}$ drastically reduced cell viability to below $49.0 \%$. The results revealed over $65 \%$ average cell viability for PEI30-DNA and PEI70-DNA complexes formulated at various N/P ratios of 1:1, 5:1, 10:1, $50: 1$, or $100: 1$ (containing $5 \mu \mathrm{g}$ of DNA). Viability declined significantly when the cells were incubated with PEI96-DNA at N/P ratios of 50:1 (60.9\%) and 100:1 (44.3\%).

\section{In vitro transfection}

The transfection efficiency of the different polymer series was tested on human HeLa cervical carcinoma cells. Increased amounts of polymer were complexed with $5 \mu \mathrm{g}$ of plasmid encoding for $\beta$-galactosidase, an enzyme that catalyzes $\beta$-galactoside hydrolysis, and applied to cells for 6 hours in the absence of serum. $\beta$-galactosidase reporter gene activity and protein content were measured for 60 hours thereafter, according to the manufacturer's instructions. For comparison, we included the commercial transfection agent Lipofectamine 2000 as a positive control in our assays because it is known to be among the most efficient in vitro transfection agents. Figure $6 \mathrm{~B}$ presents the $\beta$-galactosidase activity expression of naked DNA, PEI30-DNA, PEI70-DNA, and PEI96-DNA at different $\mathrm{N} / \mathrm{P}$ ratios.

HeLa cells treated with free $\beta$-galactosidase plasmid DNA (Figure 6B) achieved $\beta$-galactosidase activity expression of $2.84 \pm 0.18 \mathrm{mU} / \mathrm{mg}$ protein $(n=6)$. PEI30-plasmid $\beta$-galactosidase DNA gave similar $\beta$-galactosidase activity expression for all $\mathrm{N} / \mathrm{P}$ ratios $(4.45 \pm 0.46 \mathrm{mU} / \mathrm{mg}$ protein at $\mathrm{N} / \mathrm{P}$ of $1 ; 4.26 \pm 0.54 \mathrm{mU} / \mathrm{mg}$ protein at N/P of $5 ; 3.14 \pm 0.40 \mathrm{mU} /$ $\mathrm{mg}$ protein at $\mathrm{N} / \mathrm{P}$ of $10 ; 3.81 \pm 0.23 \mathrm{mU} / \mathrm{mg}$ protein at $\mathrm{N} / \mathrm{P}$ of 50 ; and $3.21 \pm 0.31 \mathrm{mU} / \mathrm{mg}$ protein at N/P of 100, respectively). At an N/P of 1, 5, and 10, PEI70-plasmid $\beta$-galactosidase DNA showed $\beta$-galactosidase expression similar to that of PEI30/DNA. However, PEI70-plasmid $\beta$-galactosidase DNA at an N/P of 50 and 100 significantly increased $\beta$-galactosidase activity expression levels by $7.98 \pm 0.08 \mathrm{mU} /$ mg protein $(\mathrm{n}=6, P<0.001$ compared with $P$ EI30/DNAtreated cells) and $13.17 \pm 2.29 \mathrm{mU} / \mathrm{mg}$ protein $(\mathrm{n}=6, P<$ 0.05 compared with PEI30/DNA-treated cells), respectively. HeLa cells transfected with PEI96-plasmid $\beta$-galactosidase DNA nanoparticles generated N/P ratios of PEI to DNAdependent response: $3.03 \pm 0.08 \mathrm{mU} / \mathrm{mg}$ protein at N/P of 1 ; 

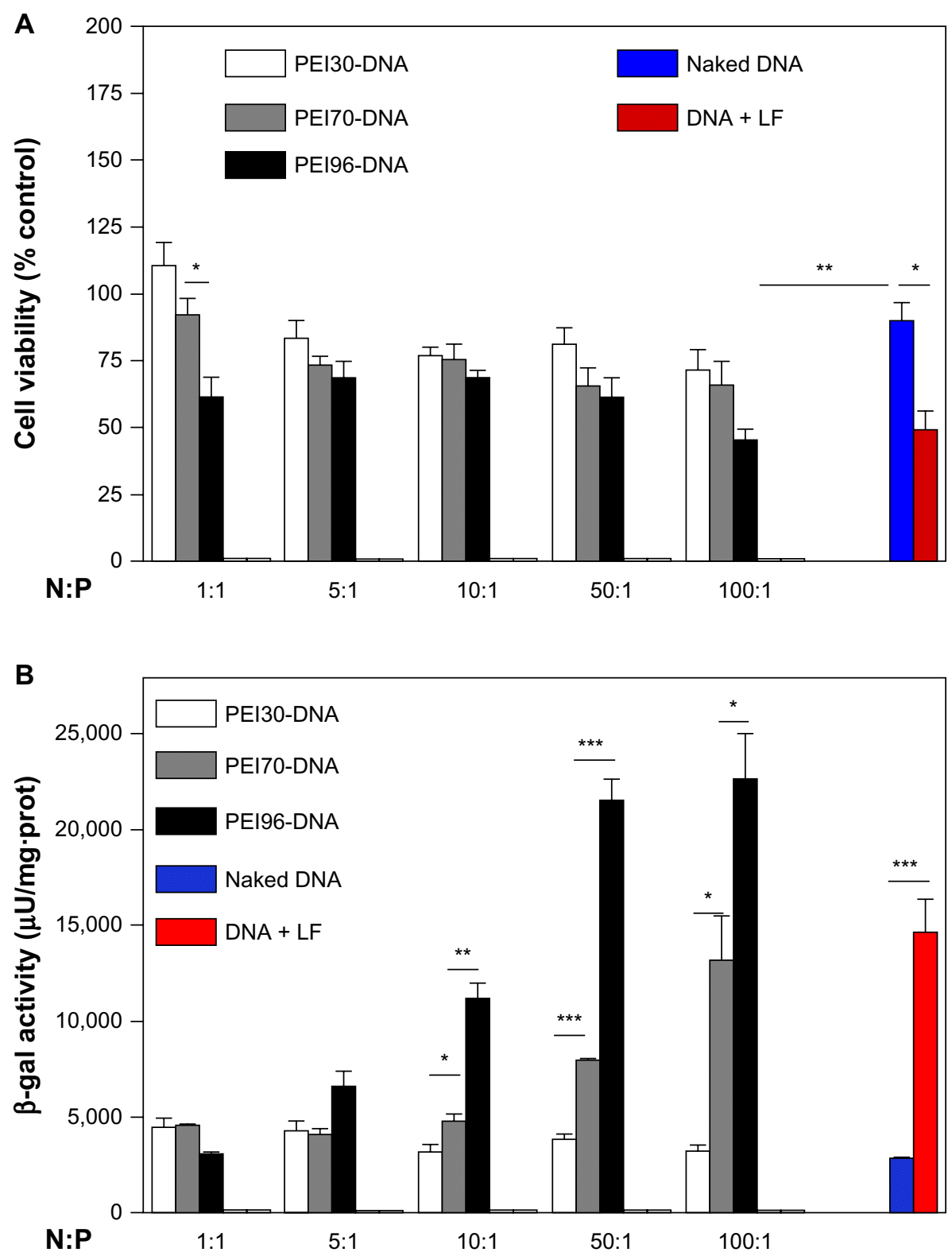

Figure 6 (A) Cell viability of HeLa transfected with either $5 \mu \mathrm{g}$ free plasmid DNA or with PEI30-DNA, PEI70-DNA, or PEI96-DNA complexes containing equivalent to $5 \mu \mathrm{g}$ of plasmid DNA. Viability is measured with the MTT assay and compared with nontreated cells, which are considered as I00. (B) Transfection efficiency in vitro. $5 \mu \mathrm{g}$ free plasmid DNA or PEI30-DNA, PEI70-DNA, or PEI96-DNA complexes containing equivalent to $5 \mu \mathrm{g}$ of plasmid DNA incubated with a HeLa cell line. The $\beta$-galactosidase reporter gene activity and protein content were measured 60 hours thereafter. The $\beta$-galactosidase reporter gene activity detection kit was used according to the manufacturer's instructions and compared with nontreated cells, which are considered as I00\%. Statistical significance was assessed using the unpaired Student's $t$-test, $* P<0.05 ; * * P<0.01 ; * * * P<0.001$.

Abbreviations: PEI, polyethylenimine; LF, Lipofectamine ${ }^{\mathrm{TM}}$; PEI30, 30\% hydrolyzed PEtOx; PEI70, 70\% hydrolyzed PEtOx; PEI96, 96\% hydrolyzed PEtOx.

$6.54 \pm 0.83 \mathrm{mU} / \mathrm{mg}$ protein at N/P of $5 ; 11.12 \pm 0.86 \mathrm{mU} / \mathrm{mg}$ protein at N/P of $10 ; 21.46 \pm 1.19 \mathrm{mU} / \mathrm{mg}$ protein at N/P of 50 ; and $22.57 \pm 2.41 \mathrm{mU} / \mathrm{mg}$ protein at N/P of 100, respectively. PEI-DNA complexes containing mismatched control plasmid DNA presented no $\beta$-galactosidase expression, confirming gene transfection efficiency (data not included).

Taken together, 30\% hydrolyzed PEI30 exhibited similarly low efficiencies at all N/P ratios tested. PEI70 and PEI96 exhibited greater transfection efficiency than naked DNA.
The transfection efficiency of PEI70 at N/P ratio of 100 was similar to that of Lipofectamine 2000. PEI96 mediated the strongest gene expression at N/P ratios of 50 and 100 .

\section{siRNA delivery}

We tested SSB-targeted siRNA provided by Merck \& Co., Inc., as validated siRNA to investigate the delivery ability of linear PEI prepared by partial acid hydrolysis of PEtOx. The ability of PEI to interact with siRNA was studied by agarose gel 
electrophoresis (Figure 7). PEI30 did not bind siRNA completely at any weight ratio (Figure 7). However, complete siRNA binding to PEI70 and PEI96 at N/P ratios of 50:1, 100, and 150 could be observed. Only PEI-siRNA at a N/P ratio of 50 was selected for size and zeta potential measurement. Twenty-four hours after complex formation, nanoparticle size was $210.6 \pm 21.9 \mathrm{~nm}, 95.10 \pm 31.3 \mathrm{~nm}$, and $88.94 \pm 43.0 \mathrm{~nm}$ for PEI30-siRNA, PEI70-siRNA, and PEI96-siRNA, respectively. Their zeta potential (24 hours after complex formation) was $9.47 \pm 0.67 \mathrm{mV}$ (PEI30-siRNA), $6.48 \pm 1.14 \mathrm{mV}$ (PEI70-siRNA), and $13.17 \pm 0.50 \mathrm{mV}$ (PEI96-siRNA).

Cell viability after a 24-hour incubation with PEI-siRNA was tested by MTT assay. As illustrated in Figure 8A, an average HeLa cell viability of over $83 \%$ was noted for free siRNAtreated cells in comparison with nontreated cells (considered as $100 \%)$. Cell viability with PEI30-DNA, PEI70-DNA, or PEI96-siRNA complexes was not significantly different from that of free siRNA-treated cells, ie, $74 \%-88 \%$.

The transfection efficiency of polymer-siRNA complexes was analyzed relative to SSB mRNA expression by real-time RT-PCR. HeLa cells (Figure $8 \mathrm{~B}$ ) treated with free SSB siRNA achieved approximately $15 \%$ knockdown of SSB mRNA expression compared with nontreated cells. No change in SSB mRNA expression was evident with PEI30-siRNA compared with nontransfected cells (negative

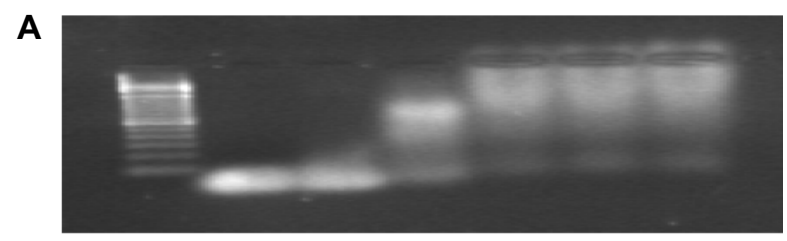

B

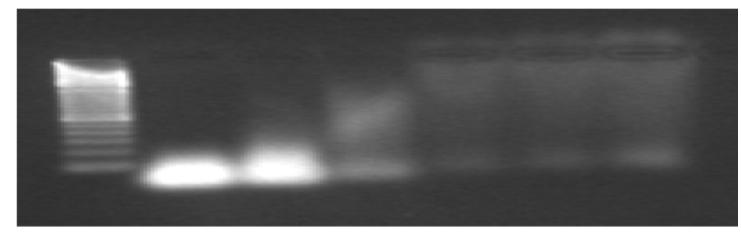

C

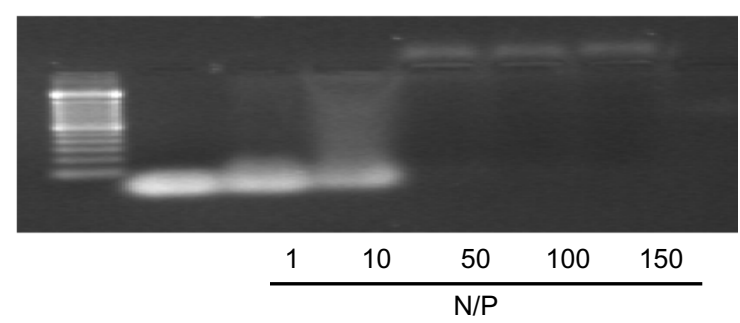

Figure 7 Electrophoresis analysis on 2\% agarose gel. (A) PEI30-siRNA, (B) PEI70siRNA, and (C) PEI96-siRNA. Effect of different percentages of acid hydrolysis of poly(2-ethyl-2-oxazoline) on siRNA binding efficiency at N/P ratios (polymer to siRNA) from I:I to I50:I, respectively. Lane I, ladder 100 bp; lane 2, free naked siRNA (I $\mu \mathrm{g} /$ lane).

Abbreviations: PEl, polyethylenimine; siRNA, small interfering RNA.

\section{A}

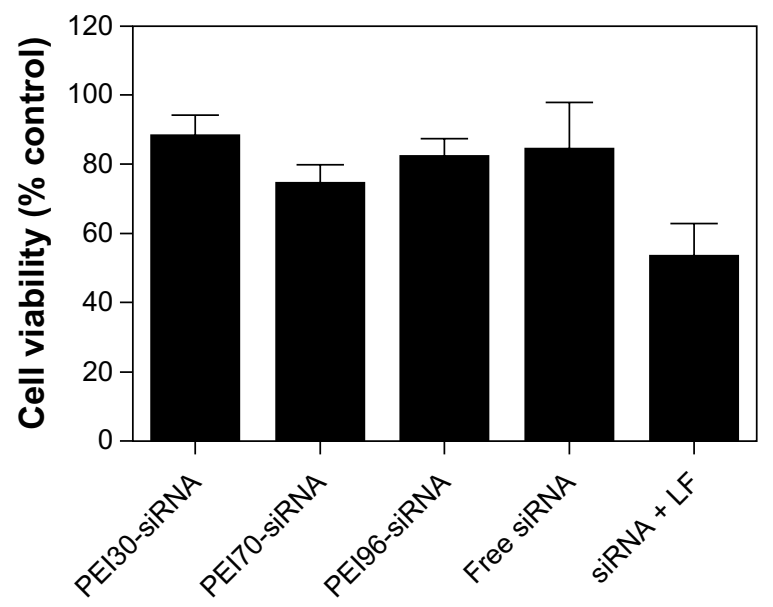

B

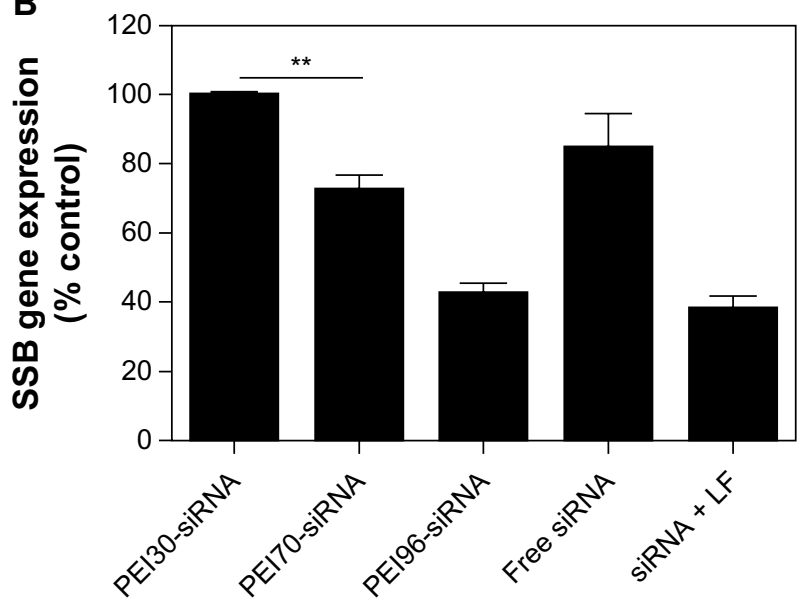

Figure 8 (A) Viability of HeLa cells transfected with either $5 \mu \mathrm{g}$ free plasmid siRNA or with PEI30-siRNA, PEI70-siRNA, or PEI96-siRNA complexes containing an equivalent to $5 \mu \mathrm{g}$ of siRNA. Viability is measured using the MTT assay and compared with nontreated cells, which are considered as 100. (B) Transfection efficiency in vitro. $5 \mu \mathrm{g}$ free siRNA or PEI30-siRNA, PEI70-siRNA, or PEI96-siRNA complexes containing an equivalent to $5 \mu \mathrm{g}$ of siRNA incubated with a HeLa cell line. SSB gene expression is measured with real-time RT-PCR and compared with nontreated cells, which are considered as $100 \%$. Statistical significance was assessed by the unpaired Student's t-test, $* * P<0.01$.

Abbreviations: PEI, polyethylenimine; MTT, 3-[4,5-dimethylthiazol-2-yl]-2,5-diphenyl tetrazolium bromide; siRNA, small interfering RNA; LF, Lipofectamine ${ }^{\circledR} 2000$.

controls). However, silencing efficiency was dependent on and increased with acid hydrolysis percentage of PEtOx. PEI70-siRNA nanoparticles exerted a $28 \%$ gene silencing effect (Figure 8B), whereas HeLa cells transfected with PEI96-siRNA nanoparticles generated 57\% gene silencing. PEI-siRNA complexes containing mismatched control siRNA presented no SSB inhibition, confirming gene silencing efficiency (data not included).

\section{Discussion}

Nonviral vectors such as PEI are attractive gene delivery systems for tumors and nonlethal diseases such as arthritis. 
Compared with viral vectors, they are noninfectious, relatively nonimmunogenic, can accommodate large DNA plasmids or RNA, and may be produced on a large scale. However, the main drawback with PEIs as nonviral gene carriers is their typically high toxicity. To reduce PEI cell toxicity, we synthesized linear PEI by partial hydrolyzation of PEtOx. In our study, linear PEI was synthesized in two steps. First, PEtOx oligomers were synthesized by living cationic polymerization of 2-ethyl-2-oxazoline. Second, linear PEI was prepared by acid hydrolysis of PEtOx with excess hydrochloric acid. Three linear PEI derivatives were obtained by sampling a single polymerization mixture at various times. Our study showed that PEtOx with up to $70 \%$ ethylenimine segments (hydrolyzed EtOx) displayed very weak cell toxicity. In addition, the charge densities of these polymers were strong enough to condense DNA/siRNA at physiologic $\mathrm{pH}$ of 7.4. The transfection efficiency of PEI70 at an N/P ratio of 100 was similar to Lipofectamine 2000. The results of our study are in good agreement with those in the literature. ${ }^{3,4,13,14}$ Poly(oxazolines) have been a subject of research since 1960, with special focus on the polymerization of 2-substituted oxazolines. Their applications include nanoscale systems such as membranes and nanoparticles, drug and gene delivery, as well as stimuli-responsive systems. ${ }^{15-17}$ Poly(oxazolines) are emerging as advanced synthetic biomaterials for DNA and RNA delivery. Their bioimmunology and cytotoxicity have been widely studied in vitro, showing that they do not exert any immunosuppressive effect or toxic behavior in cells. ${ }^{18-20}$

Research over the years has revealed that branched PEI is one of the desirable polymeric carriers of DNA-siRNA because of its superior transfection efficiency and high cytotoxicity. The high transfection efficiency of branched PEI is attributed to its large "proton sponge" effect which permits DNA-siRNA condensation under physiologic $\mathrm{pH}$ conditions. Its large buffering capacity also allows complexes of PEI-DNA and PEI-siRNA to escape from endosomes, resulting in polyplex release into the cytoplasm. Simple modification of branched PEI leads to highly efficient siRNA carriers with low toxicity by altering amines with ethyl acrylate, acetylation of primary amines, or the introduction of negatively charged propionic acid or succinic acid groups to the polymer structure. ${ }^{21}$ Linear PEI has been reported to be an effective gene carrier in vitro and in vivo, with lower cytotoxicity than branched PEI. Linear PEI is known to have toxicity as low as that of polyethylene glycol. ${ }^{20}$ In the present study, PEI30 (1 mg/mL) and PEI70 (1 mg/ $\mathrm{mL}$ ) were nontoxic compared with controls (nontreated cells). Viability decreased dramatically by $8.7 \% \pm 0.54 \%$ ( $\mathrm{n}=3, P<0.001$ ) when the cells were incubated with PEI96 $(1 \mathrm{mg} / \mathrm{mL})$ in comparison with nontreated cells. IC $_{50}$ values for PEIs of different acid hydrolysis were $14.29 \mathrm{mg} / \mathrm{mL}$ (PEI30), $7.08 \mathrm{mg} / \mathrm{mL}$ (PEI70), and $0.025 \mathrm{mg} / \mathrm{mL}$ (PEI96), respectively. These results suggest that the extent of PEtOx hydrolysis can be important for cell viability. Toxicity is mainly associated with the strong positive charge of this polycation. Our findings show that PEI30-DNA and PEI70DNA nanoparticles have lower cytotoxicity than commercial transfection agents, such as Lipofectamine 2000, even at a high N/P ratio of 100:1. Average cell viability with PEI70DNA at N/P ratios of 50 and 100 was between $65.7 \%$ and $67.6 \%$ compared with nontreated cells. The cytotoxicity observed for PEI96 with a high percentage of acid hydrolysis was similar to that of Lipofectamine 2000, which is considered to have high cell toxicity.

In general, polycations are toxic because of their strong interaction with negatively charged cell membranes. However, toxicity has to be balanced with transfection efficiency. The ability of PEI to deliver DNA and siRNA both in vitro and in vivo was reported recently. ${ }^{22-24}$ Our transfection experiment with PEI70-DNA demonstrated that similar transfection efficiency as with Lipofectamine 2000 can be obtained while lowering cytotoxicity. The influence of N/P ratio of PEI to DNA and varying hydrolysis percentages of PEtOx was explored. Thirty percent hydrolyzed PEI30 exhibited similarly low efficiencies at all N/P ratios tested. Seventy percent hydrolyzed PEI70 and $96 \%$ hydrolyzed PEI96 exhibited greater transfection efficiency than naked DNA, depending on their N/P ratios. Higher $\mathrm{N} / \mathrm{P}$ ratios of PEI70 and PEI96 provided better transfection efficiency. The N/P ratio seems to play a critical role in cell transfection. However, PEI30 and PEI96 cannot be considered as suitable transfection agents because of low transfection efficiency (PEI30) and high cellular toxicity (PEI96). Only 70\% hydrolyzed PEI70 showed higher transfection and lower cytotoxicity than the two other polymers. Taken together, it is expected that PEI70 can serve as a favorable candidate for gene delivery with both in vitro and in vivo applications.

siRNA silencing technology has been exploited in a wide range of biological studies, but has also become one of the most challenging therapeutic strategies. However, because of its poor delivery and susceptibility to nuclease degradation, siRNA-based approaches need a protective transport system. Unprotected, naked siRNAs are relatively unstable in blood and serum and have short half-lives in vivo. ${ }^{25}$ Naked 
siRNAs do not freely cross cellular membranes because of their large molecular weight (approximately $13 \mathrm{kDa}$ ) and strong anionic charge. They are rapidly degraded by nuclease.

A variety of polymer formulations have been proposed as potential carriers in the literature. Research over the years has revealed that PEI is one of the desirable polymeric carriers of DNA because of its ability to form stable complexes by electrostatic interactions with nucleic acids. It has been shown to be less effective in siRNA delivery. It is toxic at high doses. Toxicity is mainly associated with its strong positive charge, which leads to strong interaction with cell membrane surfaces. Our results show that PEI-siRNA toxicity was greatly reduced by the polymer molecular weight, charge density, and ratio of protonatable polymer amine groups to nucleic acid phosphate groups, while the ionic strength of the medium can affect electrostatic binding between siRNA and cationic polymers. In comparison with DNA delivery, binding requires higher polymer to siRNA N/P ratios. Such differences are caused by the fact that short length siRNA (21-25 base pairs) and linearity bind to PEI in a manner different to that observed with plasmid DNA. PEIs, which have known efficiency in DNA delivery, were found to be far less effective for application with siRNA. PEI30 did not show any gene knockdown. In the current study, 70\% hydrolyzed PEI70 had a 30\% gene-silencing effect. PEI96 was able to induce more than $50 \%$ silencing of the SSB gene at an siRNA of 5 $\mu \mathrm{g}$ in HeLa cells (relative to untreated cells).

\section{Conclusion}

In conclusion, linear PEIs were prepared by partial acid hydrolysis of PEtOx, which showed high efficiency in DNA delivery. In particular, PEI70 resulted in lower polymer toxicity in comparison with PEI96 (high hydrolysis percentage). PEI70 completely condensed DNA and formed nanoparticles $(120 \mathrm{~nm})$ at a PEI70 to DNA N/P ratio of 50:1. Compared with PEI30 (low hydrolysis percentage), PEI70 improved transfection efficiency. Formulation of siRNA with PEI70 induced remarkable target gene knockdown. These findings may encourage further exploration of the utility of PEI as a nonviral gene delivery vector.

\section{Acknowledgments}

This work was supported by grants from the Ministry of Science and Technology of People's Republic of China (2011DFA30790), Science and Technology Commission of Shanghai Municipality (13430710700), and the Canadian Institutes of Health Research (CCM 104888). The authors thank Merck \& Co., Inc. (West Point, PA, USA) for providing the SSB-targeted siRNA.

\section{Disclosure}

The authors report no conflicts of interest in this work.

\section{References}

1. Mintzer MA, Simanek EE. Nonviral vectors for gene delivery. Chem Rev. 2009;109:259-302.

2. Klotz IM, Royer GP, Sloniewsky AR. Macromolecule-small molecule interactions. Strong binding and cooperativity in a model synthetic polymer. Biochemistry. 1969;8:4752-4756.

3. Jeong JH, Song SH, Lim DW, Lee H, Park TG. DNA transfection using linear poly(ethylenimine) prepared by controlled acid hydrolysis of poly(2-ethyl-2-oxazoline). J Control Release. 2001;73:391-399.

4. Brissault B, Kichler A, Guis C, Leborgne C, Danos O, Cheradame H. Synthesis of linear polyethylenimine derivatives for DNA transfection. Bioconjug Chem. 2003;14:581-587.

5. Neu M, Fischer D, Kissel T. Recent advances in rational gene transfer vector design based on poly(ethylene imine) and its derivatives. J Gene Med. 2005;7:992-1009.

6. Bonnet ME, Erbacher P, Bolcato-Bellemin AL. Systemic delivery of DNA or siRNA mediated by linear polyethylenimine (L-PEI) does not induce an inflammatory response. Pharm Res. 2008;25: 2972-2982.

7. Thomas M, Lu JJ, Ge Q, Zhang C, Chen J, Klibanov AM. Full deacylation of polyethylenimine dramatically boosts its gene delivery efficiency and specificity to mouse lung. Proc Natl Acad Sci U S A. 2005;102: 5679-5684.

8. Diab C, Akiyama Y, Kataoka K, Winnik FM. Microcalorimetric study of the temperature-induced phase separation in aqueous solutions of poly(2isopropyl-2-oxazolines). Macromolecules. 2004;37(7):2556-2562.

9. Smith PK, Krohn RI, Hermanson GT, et al. Measurement of protein using bicinchoninic acid. Anal Biochem. 1985;150:76-85.

10. Bolstad AI, Eiken HG, Rosenlund B, Alarcon-Riquelme ME, Jonsson R. Increased salivary gland tissue expression of Fas, Fas ligand, cytotoxic $\mathrm{T}$ lymphocyte-associated antigen 4, and programmed cell death 1 in primary Sjogren's syndrome. Arthritis Rheum. 2003;48:174-185.

11. Kreuzer KA, Lass U, Landt O, et al. Highly sensitive and specific fluorescence reverse transcription-PCR assay for the pseudogene-free detection of beta-actin transcripts as quantitative reference. Clin Chem. 1999;45:297-300.

12. Boussif O, Lezoualc'h F, Zanta MA, et al. A versatile vector for gene and oligonucleotide transfer into cells in culture and in vivo: polyethylenimine. Proc Natl Acad Sci U S A. 1995;92:7297-7301.

13. Hsiue GH, Chiang HZ, Wang CH, Juang TM. Nonviral gene carriers based on diblock copolymers of poly(2-ethyl-2-oxazoline) and linear polyethylenimine. Bioconjug Chem. 2006;17:781-786.

14. Van Kuringen HP, Lenoir J, Adriaens E, Bender J, De Geest BG, Hoogenboom R. Partial hydrolysis of poly(2-ethyl-2-oxazoline) and potential implications for biomedical applications? Macromol Biosci. 2012;12:1114-1123.

15. Adams N, Schubert US. Poly(2-oxazolines) in biological and biomedical application contexts. Adv Drug Deliv Rev. 2007;59:1504-1520.

16. Kelly AM, Wiesbrock F. Strategies for the synthesis of poly(2-oxazoline)based hydrogels. Macromol Rapid Commun. 2012;33:1632-1647.

17. Luxenhofer R, Han Y, Schulz A, et al. Poly(2-oxazoline)s as polymer therapeutics. Macromol Rapid Commun. 2012;33:1613-1631.

18. Kronek J, Kronekova Z, Luston J, Paulovicova E, Paulovicova L, Mendrek B. In vitro bio-immunological and cytotoxicity studies of poly(2-oxazolines). J Mater Sci Mater Med. 2011;22:1725-1734.

19. Kronek J, Paulovicova E, Paulovicova L, Kronekova Z, Luston J. Immunomodulatory efficiency of poly(2-oxazolines). J Mater Sci Mater Med. 2012;23:1457-1464. 
20. Bauer M, Lautenschlaeger C, Kempe K, Tauhardt L, Schubert US, Fischer D. Poly(2-ethyl-2-oxazoline) as alternative for the stealth polymer poly(ethylene glycol): comparison of in vitro cytotoxicity and hemocompatibility. Macromol Biosci. 2012;12:986-998.

21. Zintchenko A, Philipp A, Dehshahri A, Wagner E. Simple modifications of branched PEI lead to highly efficient siRNA carriers with low toxicity. Bioconjug Chem. 2008;19:1448-1455.

22. Hsu CY, Uludag H. A simple and rapid nonviral approach to efficiently transfect primary tissue-derived cells using polyethylenimine. Nat Protoc. 2012;7:935-945.

23. Gunther M, Lipka J, Malek A, Gutsch D, Kreyling W, Aigner A. Polyethylenimines for RNAi-mediated gene targeting in vivo and siRNA delivery to the lung. Eur J Pharm Biopharm. 2011;77: $438-449$.
24. Landry B, Aliabadi HM, Samuel A, et al. Effective non-viral delivery of siRNA to acute myeloid leukemia cells with lipid-substituted polyethylenimines. PLoS One. 2012;7:e44197.

25. Gao S, Dagnaes-Hansen F, Nielsen EJ, et al. The effect of chemical modification and nanoparticle formulation on stability and biodistribution of siRNA in mice. Mol Ther. 2009;17: 1225-1233.

\section{Publish your work in this journal}

The International Journal of Nanomedicine is an international, peerreviewed journal focusing on the application of nanotechnology in diagnostics, therapeutics, and drug delivery systems throughout the biomedical field. This journal is indexed on PubMed Central, MedLine, CAS, SciSearch $\AA$, Current Contents ${ }^{\circledR} /$ Clinical Medicine,
Journal Citation Reports/Science Edition, EMBase, Scopus and the Elsevier Bibliographic databases. The manuscript management system is completely online and includes a very quick and fair peer-review system, which is all easy to use. Visit http://www.dovepress.com/ testimonials.php to read real quotes from published authors. 